\title{
Preperitoneal catheter analgesia is an effective method for pain management after colorectal surgery: the results of 100 consecutive patients
}

This article was published in the following Dove Press journal:

Local and Regional Anesthesia

9 October 2014

Number of times this article has been viewed

\author{
Ali Ozer' \\ Aysun Yılmazlar ${ }^{2}$ \\ Ersin Oztürk' \\ Tuncay Yılmazlar' \\ 'Department of General Surgery, \\ ${ }^{2}$ Department of Anesthesiology and \\ Reanimation, Faculty of Medicine, \\ Uludağ University, Görükle, Turkey
}

Background: In a previous prospective randomized trial, we showed that local anesthetic infusion using a preperitoneal catheter is an effective postoperative analgesic method following colorectal resections. Over time, we have improved the technique of preperitoneal catheter analgesia. In this prospective cohort study, we report the results of 100 consecutive patients who underwent colorectal resections.

Materials and methods: Preperitoneal catheter analgesia was performed via a multihole catheter placed in the preperitoneal space using $10 \mathrm{~mL} 0.5 \%$ levobupivacaine every 4 hours following the operation for the first 3 days. Additional analgesics were used whenever necessary. Postoperative pain was assessed with the visual analog scale score. Short-term clinical outcomes, such as need for systemic analgesics, time to first gas and stool discharge, length of hospital stay, and morbidity, particularly surgical site infections, were reported.

Results: From May 2009 to May 2010, 100 consecutive patients were recruited in the study. A total of 83 patients were operated on for malignancy, and the tumor was located in the rectum in 52 patients and in the colon in 31 patients. The median pain score was $4(0-6), 3(0-9)$, $2(0-8), 1(0-8), 1(0-6), 0(0-6)$, and $0(0-3)$ at postoperative hours $0,1,4,12,24,48$, and 72 , respectively. Additional analgesics were required in 34 patients: 21 of them required only nonsteroidal anti-inflammatory drugs, and 13 patients needed opioids additionally. The median amounts of opioid analgesics and nonsteroidal anti-inflammatory drugs were $1.76 \pm 0.78 \mathrm{mg}$ and $6.70 \pm 1.18 \mathrm{mg}$, respectively. However, almost all of the additional analgesics were given in the first 24 hours. Surgical site infections were detected in eight patients.

Conclusion: Preperitoneal catheter analgesia is an effective analgesic method. When applied and used properly, it may even be used as the sole analgesic method in some patients.

Keywords: preperitoneal, colorectal, analgesia

\section{Introduction}

An ideal method for pain management following colorectal surgery is required to control the pain that works with small amounts of the drug and has less systemic side effects. The most common painkillers used are opioids. They are effective; however, they induce vomiting and decrease the latency of the intestinal passage. Therefore, researchers focused on determining the mechanism of incisional pain to improve new models in postoperative pain management.

Studies have shown that the peritoneum has a basic role in pain formation. This role involves a local cytokine release and its sequent systemic response. Therefore, wound infiltration with local anesthetic (LA) has become a new area targeting prevention of this local response to trauma (including surgical trauma) and its systemic results. ${ }^{1-4}$
Correspondence: Ali Ozer

Department of General Surgery, Faculty of Medicine, Uludağ University, Görükle, Bursa 16059, Turkey

Email draliozerr@gmail.com 
Different catheter techniques have been used for this purpose, and studies have shown that continuous wound catheters appear to be an effective modality for management of postoperative pain. ${ }^{5}$

Wound infiltration of LA using a multihole catheter placed in the preperitoneal space has been found to improve pain relief and to accelerate patient recovery compared with systemic opioids after open colorectal surgery. ${ }^{5,6}$ Preperitoneal infusion is a promising adjunct to existing analgesic regimens following laparotomy for major colorectal surgeries. These studies suggest an alternative to significantly decrease opioid consumption. Preperitoneal catheter analgesia (PPCA) is a distinct and effective method among the different woundinfiltration techniques. ${ }^{6}$

In a previous prospective randomized trial, we showed that LA infusion using a preperitoneal catheter was an effective postoperative analgesia method following colorectal resections. ${ }^{7}$ Meanwhile, we have improved the technique of PPCA, eg, the concentration and dosage of the infusing LA, and the administration interval. In this prospective cohort study, we observe the efficacy of PPCA that was performed in 100 consecutive patients who underwent open abdominal colorectal resection. The effectiveness of PPCA was assessed as a principal analgesia method controlling postoperative pain in colorectal surgery.

\section{Materials and methods}

This study was approved by the institutional review board. A total of 100 consecutive patients between May 2009 and May 2010 who had signed a written consent form were recruited for the study. Patients who did not wish to participate in the study and patients who had undergone laparoscopic surgery were not included in the study. Also, patients in whom separate closure of the peritoneum was not possible due to previous surgery were excluded from the study.

The same colorectal surgery team performed all the colorectal procedures, even the emergency cases. Prior to the surgery, the patients were informed about the PPCA, and a written consent form was obtained from all of them. When the total number of the patients reached 100, the study was stopped.

At the end of the surgery, in all the patients who underwent the open colorectal resections via midline incisions, the peritoneum was closed with absorbable running sutures, and then a multihole catheter was placed in the preperitoneal space along the full length of the wound. For this purpose, a $45 \mathrm{~cm}$ central venous pressure catheter was inserted (Cavafix ${ }^{\circledR}$ Certo $^{\circledR}$; Braun, Melsungen, Germany) approximately $3 \mathrm{~cm}$ from the upper end of the midline incision, and holes of $2 \mathrm{~mm}$ were made all along the catheter by needle puncture in addition to the original holes. A $10 \mathrm{~mL}$ bolus of saline solution was administered via the catheter to test. After this control, the fascia layer and skin were closed, and the catheter was fastened to the skin. Another test was performed at this time with saline solution.

PPCA was performed infusing $10 \mathrm{~mL} 0.5 \%$ levobupivacaine (Chirocaine ${ }^{\circledR}, 50 \mathrm{mg}, 10 \mathrm{~mL}$ ) every 4 hours following the operation for 3 days. Postoperative analgesia was started in the operating room, and the first dose was administered there. Then, the patients were moved to the postanesthesia care unit (PACU) and assessed for pain. After that, the patients were transferred to the nursing ward, and pain assessment was carried out again. PPCA was primarily performed for postoperative pain management, but additional analgesics like nonsteroidal anti-inflammatory drugs (NSAIDs) and/or opioid analgesics were used in the PACU and nursing ward whenever necessary.

During the first 3 postoperative days, the static (at rest) pain score was measured hourly in the PACU. In the ward, pain was assessed six times daily during the postoperative 72 hours and then once daily until discharge, no matter whether the patient was at rest or on the move. Pain assessment was recorded using the visual analog scale (VAS) by a trained nurse. When a VAS score was reported as 5 or higher, the attending surgeon was informed, and an additional analgesic was administered after controlling for any technical problems related to the PPCA catheter. NSAIDs were the first choice to control the pain in addition to PPCA. When additional analgesics were administered, a second pain assessment was made after 30 minutes, and whenever the VAS score was still $\geq 5$, then an opioid analgesic was used as a second option. The VAS pain scores were reported at postoperative hours 0 (when the patient was in the PACU), 1, 4, 12, 24, 48, and 72. The time and amount of the additional analgesic requirement were also recorded prospectively.

Patients' demographics, disease characteristics, surgical features, incision type and length (longer or shorter than $25 \mathrm{~cm}$ ), clinical outcomes, and operative morbidity were recorded. In particular, the most frequent side effects of opioids, like nausea and vomiting, were assessed during the postoperative period.

Time to first passage of gas or stool, time to first oral intake, and length of hospital stay were also reported. Respiratory function was assessed by physical examination and chest X-ray, and above all atelectasia was evaluated. 


\section{Results}

During the study period, 153 patients underwent colorectal surgery. The data of 100 consecutive patients that completed the study were analyzed in this study. Eight patients did not wish to participate in the study. Forty seven patients intending to undergo laparoscopic surgery were not included in the study. Six extra patients who had undergone colorectal surgery and given written consent were also excluded from the study, because it was not possible to close the peritoneum due to the previous abdominal surgery. However, the peritoneum was successfully closed at the end of the operation for 15 participants who had had previous open abdominal surgery.

The demographics of the patients were not exceptional. Of the 100 patients, 71 were male, and the mean age was $59.6 \pm 1.95$ years for all the patients. The median body mass index value was $26.8 \mathrm{~kg} / \mathrm{m}^{2}$. In 17 patients, the indication for surgery was a benign condition, and 83 patients underwent colorectal resections for malignancy. For the cases with malignancy, the tumors were located in the colon in 31 patients and in the rectum in 52 patients. Seven patients were operated on in cases of emergency. In 48 patients, the midline incision was longer than $25 \mathrm{~cm}$. These data are summarized in Table 1.

The median VAS score was $<5$ for each interval, and thus an effective analgesic was provided to the patients (Table 2). The median VAS score in the PACU (0 hours) was 4 (0-6). In the PACU, $25 \%$ of the patients had required additional analgesics, and only a single dose of an NSAID was given. No patients received opioids in the PACU. During the first operative day, the median VAS score was over 0 but below 5. During the second and third postoperative days, the median pain score was 0 . Additionally, we noticed that the VAS scores showed no difference between rectum and colon resections (Table 2).

Table I Demographics and surgical characteristics

\begin{tabular}{ll}
\hline Age (years) & $59.6 \pm 1.95$ \\
Sex $(\mathrm{F} / \mathrm{M})$ & $29 / 7 \mathrm{I}$ \\
$\mathrm{BMI}\left(\mathrm{kg} / \mathrm{m}^{2}\right)$ & $26.8 \pm \mathrm{I} .16$ \\
Diagnosis & \\
$\quad$ Colon cancer & 31 \\
Rectum cancer & 52 \\
Benign disease & 17 \\
ASA score I/II/III/IV & $42 / 49 / 4 / 3$ \\
Elective/emergency & $93 / 7$ \\
Incision length $(>25 \mathrm{~cm})$ & 48 \\
Operative time (minutes) & $118,15 \pm 3,63$ \\
\hline
\end{tabular}

Abbreviations: F, female; M, male; BMI, body mass index; ASA, American Society of Anesthesiologists.
Table 2 Pain scores and features of additional analgesics

\begin{tabular}{llll}
\hline & $\begin{array}{l}\text { All patients } \\
(\mathbf{n}=100)\end{array}$ & $\begin{array}{l}\text { After rectum } \\
\text { resection } \\
(\mathbf{n}=\mathbf{5 5})\end{array}$ & $\begin{array}{l}\text { After colon } \\
\text { resection } \\
(\mathbf{n}=\mathbf{4 5})\end{array}$ \\
\hline VAS 0 hours & $4(0-6)$ & $4(0-6)$ & $3(0-6)$ \\
VAS I hour & $3(0-9)$ & $4(0-9)$ & $3(0-8)$ \\
VAS 4 hours & $2(0-8)$ & $3(0-8)$ & $\mathrm{I}(0-6)$ \\
VAS I2 hours & $\mathrm{I}(0-8)$ & $\mathrm{I}(0-8)$ & $\mathrm{I}(0-5)$ \\
VAS 24 hours & $\mathrm{I}(0-6)$ & $\mathrm{I}(0-5)$ & $\mathrm{I}(0-6)$ \\
VAS 48 hours & $0(0-6)$ & $0(0-3)$ & $0(0-6)$ \\
VAS 72 hours & $0(0-3)$ & $0(0-2)$ & $0(0-3)$ \\
\hline
\end{tabular}

Notes: Nonsteroidal anti-inflammatory drug consumption $(\mathrm{mg}), 6.70 \pm 1.18$ (34 patients); opioid consumption (mg) I.76 \pm 0.78 (13 patients). Numbers in the brackets refer to the minimum and maximum VAS values at the specific hour.

Abbreviation: VAS, visual analog scale.

A total of 34 patients required additional analgesics. In 21 of them, NSAIDs were sufficient to control the pain, and just one dose of the drug was sufficient. Among these patients, only one patient required one more single dose on the second postoperative day. Opioid analgesics (morphine) were necessary for 13 patients. Nine of these patients have required opioid during the first 12 hours in the postoperative period. The other four patients required opioids on the second and third postoperative days. These four patients had undergone abdominoperineal resection and had additional perineal incision that was outside the PPCA impact area. The mean amounts of NSAIDs and opioid (morphine) consumption were $6.70 \pm 1.18 \mathrm{mg}$ and $1.76 \pm 0.78 \mathrm{mg}$ respectively. The data on additional analgesics are shown in Table 2.

Clinical outcomes and morbidity are summarized in Table 3. Nausea was reported for eleven patients, and first-line antiemetic drugs were given. Two patients suffered from vomiting. Surgical site infection (SSI) was detected in eight patients. Respiratory problems (atelectasia and pneumonia) were confirmed in eight patients.

\section{Discussion}

In our previous randomized prospective trial, ${ }^{7}$ PPCA was found to be an effective analgesia method. In time, we made

Table 3 Clinical features and morbidity

\begin{tabular}{lll}
\hline Gas discharge* & & $52.04 \pm 2.07$ hours \\
Stool discharge* & & $81.13 \pm 3.33$ hours \\
Oral intake* & & $74.37 \pm 2.96$ hours \\
Morbidity & & \\
$\quad$ Nausea & $11 \%$ & \\
Vomiting & $2 \%$ & \\
SSI & $8 \%$ & \\
Respiratory & $8 \%$ & \\
\hline
\end{tabular}

Note: *Postoperative hours.

Abbreviation: SSI, surgical site infection. 
progress in technique and especially in posology. In this study, we presented the results of 100 consecutive patients who underwent open colorectal surgery and received PPCA as primary postoperative analgesia method.

Studies that focused on wound-infiltration analgesia have shown that the preperitoneal space is the correct place for catheter replacement to procure effective pain control after midline laparotomy. ${ }^{7-11}$ Despite two studies that have reported that subcutaneous LA infiltration was also efficient, ${ }^{12,13}$ other studies have not supported these results. ${ }^{14-16}$

The features of the catheter are another issue as part of PPCA. The configuration of the catheter is important to deliver infiltration of LA in the preperitoneal space. A singlelumen multiorifice catheter is mostly used for preperitoneal LA installation. There are commercially available catheters with these specifications. Unfortunately, it is not possible to find this product in our country. That is why we used a manipulated central venous pressure catheter to infuse LA. However, there is no standard catheter proven to deliver the most effective infusion of LA. For that purpose, studies are still in progress to reach a standard wound-installation catheter, ${ }^{17}$ and also comparative studies are necessary.

Another factor that may be considered for effective preperitoneal analgesia is the type of LA. Ropivacaine, bupivacaine, and levobupivacaine are the LAs that are used for PPCA. It is already known that an LA inhibits the local inflammatory response to the injury, which sensitizes nociceptive receptors and contributes to pain and hyperalgesia. Therefore, the degree of the anti-inflammatory effect of the LA seems the most important property to compare. We chose to use levobupivacaine for its long-lasting efficacy.

Posology is another important factor for PPCA. Intermittent, ${ }^{7}$ continuous, ${ }^{8,10,12}$ and patient-controlled infusions have been performed with different concentrates of LA. All of these studies considered PPCA as a part of multimodal analgesia management. However, we have aspired to use PPCA as a main method for analgesia. We already have results regarding different doses and intervals from our first study. Unfortunately, there have not been any published studies. Over time, we have tried different doses and intervals since our first study. Levobupivacaine $(0.5 \%, 10 \mathrm{~mL})$ every 4 hours provided effective pain control in our patient population. At a point when we reached the optimal delivery method for PPCA, we conducted the present study. Also, it should be noted that no special equipment is necessary for intermittent administration, as distinct from continuous infusion.

It is still a challenge to achieve optimized pain control while avoiding the side effects of opioid drugs.
Unfortunately, these drugs are still an important part of postoperative analgesia in colorectal surgery. We were obligated to use opioid in 13 patients as a rescue analgesic. Four of these patients had undergone abdominoperineal rectum resection, which requires opioids for 3 days. It is advisable to plan an additional analgesic regimen for patients who undergo abdominoperineal rectum resection, particularly for perineal incision. The significant side effects of opioids, such as narcotic-induced ileus, nausea, and vomiting, were detected in a few patients in our study.

Respiratory morbidities, such as atelectasia due to severe pain, are also a problem after open colorectal surgery. Epidural analgesia is an effective method to produce sufficient analgesia and to prevent diaphragm dysfunction. ${ }^{18}$ However, PPCA had comparable results in this area in our patient population.

No technical problems due to the catheter, such as occlusion or displacement, were reported during the study, since we had gained enough experience from our previous patients. The safety of the catheter with regard to SSI might be a concern. Lluis et al ${ }^{19}$ reported no significant difference in frequency of SSIs in relation to PPCA. It could be argued that the surgeons might be closing the incision more carefully to deliver an optimized catheter replacement. Besides, the SSI rate was $8 \%$ in our patient population, which included both emergent and elective cases, which is an acceptable rate.

Principally, we propose PPCA for all patients after open colorectal surgery via midline laparotomy except patients in whom separate closure of the peritoneum was not possible due to previous surgery. PPCA can be administered as the main analgesic method, and additional analgesic methods might be used if necessary, based on the VAS scores. With respect to our results, $10 \mathrm{~mL}$ of $0.5 \%$ levobupivacaine every 4 hours provided effective pain control. Sixty-six percent of patients did not require any additional analgesic method.

Epidural analgesia is undoubtedly a gold-standard analgesic modality following abdominal surgery. However, the necessity of specific equipment and a qualified team restricts its practical use, particularly for surgeons who work in rural areas. PPCA might be sufficient in a certain number of patients as the sole analgesic method when applied and used properly following open colorectal surgery. In addition, for other patients, it might be a powerful tool for the multimodal management of analgesia following colorectal surgery.

\section{Disclosure}

The authors report no conflicts of interest in this work. 


\section{References}

1. Brennan TJ, Zahn PK, Pogatzki-Zahn EM. Mechanisms of incisional pain. Anesthesiol Clin North America. 2005;23:1-20.

2. van Berge Henegouwen MI, van der Poll T, van Deventer SJ, Gouma DJ. Peritoneal cytokine release after gastrointestinal surgery and postoperative complications. Am J Surg. 1998;175:311-316.

3. Sammour T, Kahokehr A, Soop M, Hill AG. Peritoneal damage: the inflammatory response and clinical implications of the neuro-immuno-humoral axis. World J Surg. 2010;34:704-720.

4. Scott NB. Wound infiltration for surgery. Anaesthesia. 2010;65: 67-75.

5. Liu SS, Richman JM, Thirlby RC, Wu CL. Efficacy of continuous wound catheters delivering local anesthetic for postoperative analgesia: a quantitative and qualitative systematic review of randomized controlled trials. J Am Coll Surg. 2006;203:914-932.

6. KarthikesalingamA, Walsh SR, Markar SR, Sadat U, Tang TY, Malata CM. Continuous wound infusion of local anaesthetic agents following colorectal surgery: systematic review and meta-analysis. World $J$ Gastroenterol. 2008;14:5301-5302.

7. Ozturk E, Yilmazlar A, Coskun F, Isik O, Yilmazlar T. The beneficial effects of preperitoneal catheter analgesia following colon and rectal resections: a prospective, randomized, double-blind, placebo-controlled study. Tech Coloproctol. 2011;15:331-336.

8. Beaussier M, El'Ayoubi H, Schiffer E, et al. Continuous preperitoneal infusion of ropivacaine provides effective analgesia and accelerates recovery after colorectal surgery: a randomized, double blind, placebocontrolled study. Anesthesiology. 2007;107:461-468.

9. Abadir AR, Nicolas F, Gharabawy R, Shah T, Michael R. Efficacy of postoperative continuous wound infiltration with local anesthetic after major abdominal surgery. Proc West Pharmacol Soc. 2009;52:35-38.

10. Gross ME, Nelson ET, Mone MC, et al. A comparison of postoperative outcomes utilizing a continuous preperitoneal infusion versus epidural for midline laparotomy. Am J Surg. 2011;202:765-769.
11. Bertoglio S, Fabiani F, Negri PD, et al. The postoperative analgesic efficacy of preperitoneal continuous wound infusion compared to epidural continuous infusion with local anesthetics after colorectal cancer surgery: a randomized controlled multicenter study. Anesth Analg. 2012;115:1442-1450.

12. Cheong WK, Seow-Choen F, Eu KW, Tang CL, Heah SM. Randomized clinical trial of local bupivacaine perfusion versus parenteral morphine infusion for pain relief after laparotomy. Br J Surg. 2001;88:357-359.

13. Sistla SC, Sibal AK, Ravishankar M. Intermittent wound perfusion for postoperative pain relief following upper abdominal surgery: a surgeon's perspective. Pain Pract. 2009;9:65-70.

14. Fredman B, Zohar E, Tarabykin A, et al. Bupivacaine wound instillation via an electronic patient-controlled analgesia device and a double catheter system does not decrease postoperative pain or opioid requirements after major abdominal surgery. Anesth Analg. 2001;92:189-193.

15. Polglase AL, McMurrick PJ, Simpson PJ, et al. Continuous wound infusion of local anesthetic for the control of pain after elective abdominal colorectal surgery. Dis Colon Rectum. 2007;50:2158-2167.

16. Baig MK1, Zmora O, Derdemezi J, Weiss EG, Nogueras JJ, Wexner SD. Use of the ON-Q pain management system is associated with decreased postoperative analgesic requirement: double blind randomized placebo pilot study. J Am Coll Surg. 2006;202:297-305.

17. Nishiyama T. Efficacy of a new four-lumen multi-oriface wound catheter. Int J Adv Med Sci. 2013;1:37-40.

18. Beaussier M, El'ayoubi H, Rollin M, et al. Parietal analgesia decreases postoperative diaphragm dysfunction induced by abdominal surgery: a physiologic study. Reg Anesth Pain Med. 2009;34:393-397.

19. Lluis F, Romero Simó M, Márquez Peiró JF, Selva Otaolaurruchi J, Zarco A. [Safety of a multiperforated catheter implanted in the surgical wound for the continuous infusion of local anaesthetics in post-operative analgesia]. Cir Esp. 2011;89:613-617. Spanish.
Local and Regional Anesthesia

\section{Publish your work in this journal}

Local and Regional Anesthesia is an international, peer-reviewed, open access journal publishing on the development, pharmacology, delivery and targeting and clinical use of local and regional anesthetics and analgesics. The journal welcomes submitted papers covering original research, basic science, clinical studies, reviews \& evaluations,

\section{Dovepress}

guidelines, expert opinion and commentary, case reports and extended reports. The manuscript management system is completely online and includes a very quick and fair peer-review system, which is all easy to use. Visit http://www.dovepress.com/testimonials.php to read real quotes from published authors. 